\title{
El Sexenio Democrático en el proceso de modernización de la España contemporánea
}

The "Democratic Sexenio" in the modernization process of Modern Spain Le "Sexennat démocratique" dans le processus de modernisation de l'Espagne contemporaine

Juan Sisinio Pérez Garzón

\section{OpenEdition}

Journals

Edición electrónica

URL: http://journals.openedition.org/bhce/1428

DOI: 10.4000/bhce.1428

ISSN: 1968-3723

Editor

Presses Universitaires de Provence

Referencia electrónica

Juan Sisinio Pérez Garzón, «El Sexenio Democrático en el proceso de modernización de la España contemporánea », Bulletin d'Histoire Contemporaine de l'Espagne [En línea], 55 | 2020, Publicado el 01 septiembre 2020, consultado el 28 noviembre 2020. URL : http://journals.openedition.org/bhce/1428 ; DOI : https://doi.org/10.4000/bhce.1428

Este documento fue generado automáticamente el 28 noviembre 2020.

Bulletin d'histoire contemporaine de l'Espagne 


\title{
El Sexenio Democrático en el proceso de modernización de la España contemporánea
}

\author{
The "Democratic Sexenio" in the modernization process of Modern Spain \\ Le "Sexennat démocratique" dans le processus de modernisation de l'Espagne \\ contemporaine
}

Juan Sisinio Pérez Garzón

1 Lo que entendemos por modernización política y socioeconómica ha constituido el leitmotiv de la historia contemporánea de España desde la generación de los ilustrados del siglo xviII. No fue un proceso unilineal ni pacífico. Su partida de nacimiento puede fecharse en las Cortes de Cádiz de 1810 cuando, por primera vez, se proclamó que «la soberanía reside esencialmente en la nación y por lo mismo pertenece a ésta exclusivamente el derecho de establecer sus leyes fundamentales». Con este principio, plasmado en la Constitución de 1812, se subvirtieron siglos de poder absoluto y de privilegios feudales. Comenzó así una nueva etapa de transformaciones que, por otra parte, afectaron a todos los países occidentales.

2 En efecto, para comprender los significados del siglo XIX, habría que establecer un arco cronológico desde la década de 1770 hasta los años 1914-1917. Ese largo siglo XIX albergó cuatro novedades decisivas. La primera, la revolución industrial, que modificó radicalmente las relaciones sociales y económicas en los países occidentales y generó el capitalismo como fuerza expansiva que repercutió en todos los rincones del planeta. En efecto, el ferrocarril y los barcos de vapor, el telégrafo y los cables submarinos crearon por primera vez un mundo global. La segunda novedad consistió en las revoluciones liberales que borraron siglos de historia absolutista y de monopolios aristocráticos para implantar la libertad y la igualdad como principios de toda sociedad. Ambas revoluciones, la económico-tecnológica y la política, supusieron una tercera novedad: el ascenso de la burguesía como clase dominante y el desarrollo y organización de los trabajadores como clase social con intereses propios. Por último, la cuarta novedad fue 
el establecimiento de la nación como espacio desde el cual organizar los Estados, los mercados, las clases sociales y las culturas, con el consiguiente desarrollo de los nacionalismos como ideología omnipresente en las distintas facetas de la vida de las sociedades.

3 La palabra "progreso» jugó un papel clave para explicar tales novedades. Predominó la idea de que se entraba en una etapa de ilustración política y cultural, de abundancia económica e innovaciones tecnológicas y, en definitiva, de aceleración social hacia un nuevo futuro. Fue un tiempo de constantes revoluciones: en la primera mitad del siglo, la de los burgueses contra los privilegios feudales; más tarde, la emancipación de los obreros, la libertad de los esclavos, la igualdad de las mujeres... Luchas, en definitiva, por un mundo más libre. Todas las formas de organización estatal fueron zarandeadas, se desplegaron nuevos idearios junto al liberalismo y surgieron así el socialismo, el feminismo, el anarquismo... Los partidos y los sindicatos tomaron la escena política y social junto con la prensa y la «opinión pública». Se hablaba en nombre de la nación y del pueblo, dos palabras que comenzaron a movilizar a masas de gentes y se convirtieron en los conceptos legitimadores del poder, de la guerra y también de nuevas éticas sociales.

4 Estas novedades han sido catalogadas con el término de «modernización». Ello no significa que lo antiguo desapareciera por el sumidero de la historia, pues pervivió hasta los inicios del siglo XX. Dicho proceso no se desarrolló de manera homogénea por países o continentes. Sería más lógico, por tanto, pensar en «múltiples modernidades» -como apuntó Eisenstadt-, porque no hubo un camino único para el despliegue de un capitalismo que, tal y como en la temprana fecha de 1848 dos jóvenes revolucionarios, Marx y Engels, diagnosticaron como un sistema con tal capacidad de cambio e innovación que desintegraría todo lo antiguo y lograría «desvanecer todo lo sólido en el aire».

5 En este contexto hay que entender lo que significó el Sexenio Democrático que transcurrió entre 1868 y 1874 . No fue un paréntesis, como a veces parece en los manuales y relatos de la historia de España, sino, por el contrario, la apertura de una nueva etapa en la que adquirieron protagonismo nuevas voces sociales y unos idearios políticos que sembraron aspiraciones y retos que persisten en la actualidad ${ }^{1}$.

\section{Revolución con nombres propios y cuestiones inéditas}

6 En septiembre de 1868 tuvo lugar una revolución que recibió el calificativo de «gloriosa» por haber cambiado el rumbo político sin cataclismos violentos. Cientos de miles de personas se lanzaron a las calles, en manifestaciones, en barricadas, armándose como voluntarios de la libertad para defender a los nuevos líderes políticos, progresistas y republicanos, que, constituidos en juntas soberanas en apoyo del pronunciamiento militar, desplazaban una monarquía que sólo servía para las camarillas de la familia real. Pero no sólo era la fiesta del pueblo que recuperaba la soberanía y la expresaba exigiendo el sufragio universal (masculino), sino que además suponía la salida a la palestra pública de una generación rica y plural de personajes sobre cuyo compromiso democrático y cultural se construirían las siguientes generaciones políticas de 1898 y de 1914. 
7 Tal fue la euforia colectiva de regeneración nacional, tal la unanimidad social en el grito de abajo lo existente, tal fue el anhelo de una España con honra. Por primera vez en España se proclamaba por doquier que los derechos humanos eran «imprescriptibles, inalienables e ilegislables», que la soberanía solo era nacional si se organizaba como popular y democrática, que la cultura era tan libre como plural, y que toda la sociedad debía organizarse sobre principios de justicia y organización equitativa de una riqueza definida como nacional, pero hasta entonces acaparada por unos pocos. En este sentido, el ambiente político y cultural del sexenio no puede comprenderse si no se tienen en cuenta dos novedades, la implantación del sufragio universal masculino y la eclosión de libertades en todos los ámbitos sociales, con la prensa como intérprete del surgimiento de nuevos retos.

8 Para comprender los cambios que se desplegaron a partir de 1868 puede ser ilustrativo recordar los nombres de los intelectuales y políticos de aquella generación que impulsó el tránsito de Estado liberal a un Estado democrático de derecho, meta que, a pesar de ciertos retrocesos posteriores, a la larga se acabaría implantando. Cabría destacar a dos personalidades, a Francisco Pi y Margall y Francisco Giner de los Ríos. No estaban solos. Justo en estos años la universidad española, creada como institución pública por los liberales gaditanos, se había convertido en vivero de ideas y de renovación intelectual. Cierto es que, debido al centralismo sobre el que giró la creación del Estado liberal, la universidad de Madrid, oficialmente llamada Central, tuvo mayor relevancia y en sus cátedras se encontraban aquellos intelectuales que, bajo la influencia de Sanz del Río, se conocen como krausopositivistas. En su nómina estaban desde el rector Fernando de Castro y los catedráticos Segismundo Moret, Joaquín M. a Sanromá, Montero Ríos, Francisco de Paula Canalejas, Miguel Morayta, Eduardo Chao y Rafael M. de Labra, hasta los presidentes de la República, Castelar y Salmerón.

9 Fueron un grupo de presión tan minoritario como influyente, al que se unían catedráticos de otras universidades españolas y escritores que se deben incluir en esta generación, como Leopoldo Alas, Antonio Machado Álvarez, alias Demófilo, o Benito Pérez Galdós. Defendieron valores democráticos, los derechos humanos, las ideas de progreso y de igualdad, la promoción cultural de las mujeres y de las clases trabajadoras, la abolición de la esclavitud, la supresión de la pena de muerte y un concepto penal de reinserción social, ideas que ellos y sus seguidores divulgaban en la prensa. Intelectualmente estaban influenciados por el pensamiento hegeliano, recibido a través del krausismo de Sanz del Río, y por las novedades del positivismo de Comte, el pactismo soberanista y social de Proudhon, el romanticismo revolucionario de Víctor Hugo (auténtica luminaria de la Europa del momento) y sobre todo por los avances científicos de un siglo en plena euforia de conquistas técnicas. Además, crearon el concepto de «España con honra», fraguaron un nacionalismo moderno, democrático, plural, en el que incluso hubo ocasión de plantearse la alternativa federal con una estructura política que no está lejana de la que hoy tiene España.

Junto a estas élites, surgieron nuevos circuitos culturales muy decisivos para llegar a unas capas populares con expectativas de mejora. En un país donde sólo un 30 por ciento sabía leer y escribir plenamente, los ateneos obreros organizados por los republicanos irradiaron nuevas ideas y extendieron la cultura hasta donde el sistema público educativo no alcanzaba por precario. Desde 1869 además se abrieron a las mujeres. En este sentido, las libertades del Sexenio Democrático supusieron el despliegue de multitud de iniciativas en la enseñanza que sustituyeron la uniformidad 
del anterior Estado confesional. Se produjo un interesante proceso de descentralización educativa, se abolieron textos obligatorios y controles y se reconoció el derecho de enseñar y fundar centros docentes a todos. Surgieron universidades libres, subvencionadas por diputaciones y ayuntamientos, e institutos de secundaria en localidades que no eran las capitales de provincia, sin más limitaciones que la moral y la higiene.

11 En ese sentido, hay que enfatizar que durante el Sexenio comenzó, aunque tímidamente, el cambio del papel de la mujer en la sociedad. En concreto, hubo dos mujeres que destacaron, Emilia Pardo Bazán en el ámbito cultural literario y Concepción Arenal en el social de las reformas penales y estudios sobre la mujer. Además, desde el gobierno de Ruiz Zorrilla en 1870, se abrió la enseñanza secundaria a las mujeres, lo que facilitaría el posterior acceso a la universidad. Conviene incluir la regulación del matrimonio civil, que suponía la secularización de las relaciones maritales. En la vida política ya habían participado mujeres desde hacía décadas, sobre todo en los motines contra las quintas y contra los consumos, pero en el sexenio tomaron un nuevo protagonismo en los clubes republicanos, e incluso lograron entrar en la masonería.

Eran cambios en los marcos culturales de una España que se abría a horizontes de democratización. Así, en lo que se refiere a la creación cultural, se impuso el realismo literario con tendencia al naturalismo, con un abierto compromiso político por parte de los escritores. En distintas tendencias políticas militaron los novelistas Pérez Galdós, Juan Valera, Alarcón y Pereda... El poeta Núñez de Arce fue un revolucionario activo en septiembre de 1868, redactó manifiestos y fue elegido diputado. Otro miembro de esta generación fue Echegaray, ministro de Fomento en 1869, que acaparó la escena de tal modo que el tradicionalista Tamayo y Baus tuvo que retirarse en 1870. Por su parte, Campoamor, comprometido con los conservadores, logró un éxito rotundo.

13 En música adquirió nuevos impulsos el género chico, que se renovó como música popular de la nación española y en este sexenio se contabilizaron más de doscientos estrenos al año en Madrid. La regeneración nacional, con la consiguiente relectura del pasado, también se hizo norma en las bellas artes. Así, la pintura histórica triunfó de la mano de Eduardo Rosales, Antonio Gisbert, Casado del Alisal y Francisco Pradilla, mientras que en arquitectura siguió el dominio del historicismo romántico a la búsqueda y exaltación de lo propio nacional y del pintoresquismo españolista. La revolución se comprobó de modo rotundo en el urbanismo. 1868 fue el año de derribo de las murallas de todas las ciudades, excepto las de Ávila, Lugo y Toledo. Sintieron la urgente necesidad de borrar rastros feudales y modernizar el espacio social urbano. De ahora son los dos planes de ensanches más influyentes, con las consiguientes teorizaciones urbanísticas, el de Castro para Madrid y el de Cerdá para Barcelona, en vísperas ambos de la revolución de 1868 .

14 Por lo demás, fue la primera vez en la historia de España en que no hubo censura prácticamente para la difusión de las ideas. Supieron sobrevivir los grandes periódicos anteriores, como el conservador La Época, fundado en 1849, o el progresista La Iberia, de 1854. Pero la libertad permitió el florecimiento de la prensa republicana y la más novedosa, la internacionalista, ciudad por ciudad. Hubo también una prensa radicalmente tradicionalista, la carlista, de combate y con carácter local, salvo $L a$ Esperanza, de ámbito nacional. Los periódicos republicanos, por el contrario, además de extender sus doctrinas, usaron la prensa como foro para el debate de ideas y entre sus 
distintas tendencias. La mayoría se editaron en Madrid con carácter nacional, como La Discusión, de Sixto Cámara, y luego El Pueblo, La Igualdad, La Federación Española, La República Federal, etc. Hubo gran competencia, con vida efímera en bastantes casos, pero tan enorme cantidad de prensa fue cualitativamente decisiva para la renovación de ideas y propuestas. Baste recordar que, por ejemplo, en Madrid, en 1867, había 17 revistas y periódicos políticos, pero en 1870 subían a 28 y en 1873 a 43. La prensa republicana fue la más vendida y extendida, seguida por la carlista. Los internacionalistas, por su parte, hicieron una prensa de propaganda de su ideario, sometida a continuos cierres gubernativos. Los títulos de los periódicos ya definían por sí solos sus propósitos: La Solidaridad, La Federación, La Emancipación, El Obrero...

Se desarrolló también una prensa de carácter regional con el afán de anudar identidades culturales diferenciadas. En algunos casos fueron embriones de futuros planteamientos nacionalistas, como el periódico El Estado Catalán, de Almirall, o La Andalucía, de Tubino. También se editaron semanarios para públicos de nivel cultural alto, o con afán de extender ese nivel cultural, la mayoría editados en Madrid, con excepciones como El Hispalense en Sevilla, y con un peso decisivo de los impulsados por republicanos, entre los que destacó La Ilustración Republicana Federal, editada por Rodríguez Solís, con artículos de Pi y Margall sobre pintura, o con poesías dedicadas a los avances técnicos y científicos. La cabecera de dicho semanario simbolizaba la marcha ascendente de la ciencia y el progreso. Los republicanos publicaron además otras revistas como La Federación Española, y La Justicia Social, especializada dar noticias de los clubes, y en la prensa republicana, en general, se insertaba folletines, con obras de Víctor Hugo, Lamartine o la Vida de Jesús de Strauss y Renan. En este aspecto de propaganda de ideas no se puede obviar el decisivo influjo que tuvieron los publicistas republicanos Garrido, Orense y Castelar, o el carlista Aparisi y Guijarro.

Por otra parte, el sufragio universal masculino obligó a todos a cambiar las técnicas propagandísticas e hizo del club la unidad pública de la vida social de los núcleos urbanos. El club surgió por iniciativa de los republicanos, defensores del sufragio universal y de la soberanía popular, partidarios, en consecuencia, de extender la cultura y la formación educativa a obreros y mujeres. Frente a las tertulias de los notables de los círculos liberales asentados desde la década de 1840, el club adquirió un carácter popular de resonancias revolucionarias para las clases acomodadas. Sólo los nombres que adoptaban ya provocaban la precaución de los conservadores: El Club rojo, La Montaña, Los Hijos de Padilla.... Siguieron la senda de lo que ya bastantes liberales habían practicado en el trienio constitucional (1820-1823). No tenían sedes propias, sino habitaciones alquiladas, no eran ricos, pero se hicieron famosos algunos como el de la plaza Antón Martín, centro de obreros radicales, presidido por Adolfo Joaritzi, activista destacado en varios frentes. Debatían, redactaban periódicos y folletos, preparaban actuaciones o concentraciones de los Voluntarios de la Libertad, y, en definitiva, influían en el rumbo del partido republicano federal que era el que mayor agitación política desarrolló en estos años por todas las poblaciones españolas. Dentro de los clubes votaban a partir de los 20 años y decidían candidatos para los ayuntamientos y para las Cortes. Además, era incompatible ser presidente de un club con algún puesto en el partido republicano. En el Cádiz de Fermín Salvoechea, por ejemplo, organizaron clubes diferentes para obreros y para mujeres, otro para los jóvenes y uno educativo, gratis para niños y obreros. También se institucionalizaron en bastantes casos como casinos republicanos, auténtica alternativa al casino de los propietarios. 


\section{Eclosión juntera y exigencias sociales} desde las Cortes de Cádiz, como eran la cuestión de los señoríos y del reparto de tierras, más otros surgidos al no cumplirse la igualdad prometida, como las quintas y los impuestos; eso sin contar que desde 1837 había quedado pendiente el estatuto y los derechos de las colonias en el Caribe y Filipinas. En todo caso, las juntas de fuerzas políticas y ciudadanas constituidas en septiembre de 1868 fueron las que abrieron el camino al triunfo del pronunciamiento militar y marcaron el giro democrático del nuevo gobierno provisional, aunque no sin tensiones. demócratas que, en gran parte, a su vez, eran republicanos federales. En sus distintos manifiestos proclamaron y exigieron el sufragio universal masculino, libertades de cultos, de enseñanza, de reunión y asociación, de imprenta (sin legislación especial de ningún tipo), junto a la inviolabilidad del domicilio y de la correspondencia, la seguridad individual, la abolición de la pena de muerte, el juicio por jurados y la inamovilidad judicial. Eran medidas para asentar los derechos humanos como base de un sistema político democrático. Además, se criticaba el centralismo del Estado organizado por los moderados y se requería la inmediata descentralización de poderes para devolver la autonomía al municipio y a la provincia.

19 A esto se añadieron dos exigencias muy sentidas por todas las clases populares, la abolición de las quintas y matrícula de mar, auténtico tributo de sangre para los pobres, y la supresión de los tributos conocidos como "consumos" y de los impuestos sobre el tabaco y la sal. Incluso hubo Juntas en que los republicanos, imbuidos ya de ideas socialistas, incluyeron el derecho al trabajo como reivindicación para el nuevo Estado. En algunos casos, hubo medidas que respondían a la sociología peculiar de la ciudad. Tal fue el caso de Cádiz, cuya Junta rebajó un tercio los derechos de importación, o la de Barcelona que los rebajó un 50\% para la importación de materias primas.

ma, por encima de las diferentes coaliciones sociales que impulsaron cada Junta, este movimiento juntero albergó un componente federal que ya había apuntado en la primera eclosión juntera acaecida en 1808 y en sucesivos movimientos similares en $1835,1836,1840$ y 1854. Ahora bien, el proceso electoral abierto con el decreto de 9 de noviembre de 1868 al convocar Cortes constituyentes mediante el voto de todos los varones con más de 25 años marcó las distancias entre dos grandes bloques. Por un lado, la coalición de tres partidos, el unionista de Serrano, el progresista de Prim y Sagasta y el democrático de Rivero y Martos, con el citado programa de sufragio universal, monarquía, libertades y orden para la modernización nacional. Por otra parte, los republicanos que bajo el concepto de «la Federal» resumían todo un programa de organización republicana federal del Estado y de reformas para redistribuir la riqueza y mejorar la vida de las clases populares. Fue un momento políticamente nuevo, con dos formas de concebir el proceso de modernización.

Así, ya en enero de 1869, en vísperas de las elecciones a diputados para las Cortes Constituyentes, el clima era definitivamente de hostilidad entre el gobierno y los federales. El mes anterior, en diciembre, los resultados de las elecciones municipales reflejaron la distribución geográfica de las diferentes fuerzas políticas. Los republicanos habían logrado la mayoría en 20 capitales: Alicante, Barcelona, Castellón, Córdoba,

Bulletin d'Histoire Contemporaine de l'Espagne, 55 | 2020 
Coruña, Huelva, Huesca, Jaén, Lérida, Málaga, Murcia, Orense, Santander, Sevilla, Tarragona, Teruel, Toledo, Valencia, Valladolid, Zaragoza y Cádiz. Sin embargo, en las elecciones a Cortes constituyentes, celebradas en enero de 1869, por primera vez casi cinco millones de varones mayores de 25 años eligieron a una cámara soberana y constituyente con voto directo y secreto y dieron el triunfo a la coalición gubernamental monárquica con 160 escaños para los progresistas del partido de Prim y Sagasta, 80 para los unionistas de Serrano, y 40 para los demócratas de Rivero. Los republicanos federales lograron 80 escaños y los unitarios obtuvieron dos, tras haber hecho una campaña en la que exigieron el voto a los 21 años. Por otra parte, los carlistas obtuvieron un grupo significativo, con 30 escaños, entre ellos tres para eclesiásticos ultras, el cardenal de Santiago, el obispo de Jaén y el canónigo Manterola, de Vitoria.

Las primeras medidas que abordaron las Cortes constituyentes, en febrero de 1869, no fueron precisamente populares. La primera, ante la guerra no declarada de Cuba, consistía en un nuevo alistamiento de 25.000 jóvenes por el sistema de quintas tan aborrecido y por cuya abolición tanta gente había luchado en el pasado septiembre. La segunda medida, beneficiosa para los especuladores, era el empréstito de 100 millones de escudos efectivos. También se organizó la comisión constitucional presidida por el líder progresista Salustiano Olózaga, e integrada, entre otros, por unionistas como Ríos Rosas, Posada Herrera o Manuel Silvela, con progresistas como Montero Ríos y Vega Armijo, y demócratas como Martos y Moret. En veinticinco días redactaron un texto del que resaltamos tanto sus características como los puntos más debatidos.

\section{Novedades en la Constitución de 1869 y el federalismo como reto}

23 Se puede afirmar que la Constitución de 1869 fue el primer código democrático de la historia de España, y se adelantó en bastantes aspectos al resto de Europa. Junto al sufragio universal masculino, secreto y directo, se estableció una detallada relación de derechos ciudadanos con carácter de «ilegislables e imprescriptibles», garantizados para evitar las tentaciones autoritarias o las pretensiones del Estado de doblegar las libertades personales. Por eso, el título I de la Constitución abarcaba casi un tercio del texto $\mathrm{y}$, junto a las clásicas libertades políticas de expresión, imprenta e ideas, se determinó el derecho de reunión y «asociación pacífica», la inviolabilidad de la correspondencia, la ampliación de las libertades individuales al pensamiento y enseñanza y al culto público de cualquier religión, o, por ejemplo, la libertad de trabajo para los extranjeros. Los derechos de reunión y asociación abrieron la puerta para el despegue del sindicalismo, y las nuevas libertades permitieron el florecimiento educativo de unos años que marcaron el rumbo del pensamiento y de la ciencia en España, con la expansión de nuevas teorías, sobre todo del positivismo y de las ideologías anarquista y marxista. Por otra parte, aunque los republicanos no lograron la explícita separación del Estado y de la iglesia católica, sin embargo, el Estado por primera vez no fue confesional y se permitió la libertad de cultos de cualquier creencia, aunque, en contrapartida, mantuvo los gastos del clero y del culto católicos.

Hubo más novedades. Se recuperó el poder del legislativo sobre el ejecutivo que había establecido la Constitución de 1812, el poder del monarca o jefe del Estado quedó sujeto al correspondiente gobierno y sobre todo se realizó la definitiva independencia del 
poder judicial cuya posterior organización con la ley de 1870 aportó el sistema de oposición para ingresar en la carrera judicial. También se implantó el juicio por jurados populares y la acción pública contra aquellos jueces que delinquieran en el ejercicio de su función. Se recuperó el protagonismo de ayuntamientos y diputaciones, ya previsto en el texto de 1812, con alcaldes elegidos por sufragio universal. Sin embargo, quedaron sin resolver o expuestos con ambigüedad premeditada el estatuto de las colonias, la relación entre ejército permanente y milicias ciudadanas, y nada menos que el principio de contribución proporcional en la hacienda...

Lo más decisivo fue que, al abrir las compuertas de las libertades, eclosionaron programas, propuestas y aspiraciones. La democracia constituyó en sí misma tal novedad que los conflictos amasados y amagados en las décadas anteriores se manifestaron con claridad como derechos ciudadanos incuestionables frente al Estado. En este sentido hay que recordar el proceso movilizador que desencadenaron los líderes republicanos por toda la geografía española en la primavera de 1869. No por casualidad eran conocidos como federales, más que como republicanos. No procede pormenorizar el desarrollo de las acciones del movimiento federalista. Baste con recordar la iniciativa de Valentí Almirall que promovió la firma en Tortosa de un pacto federal entre los comités del partido republicano de Cataluña, Aragón, País Valenciano y Baleares. Ese plan se extendió, se firmó un pacto similar en Córdoba, congregando a los comités federales de Andalucía, Extremadura y Murcia, aunque en esta ocasión se aprobó el derecho a la insurrección, si los principios de la «revolución española» se atacaban y si los medios legales no fuesen suficientes para alcanzar la república federal.

Se sumaron los comités de ambas Castillas y de las provincias de León que firmaron en Valladolid un pacto federal en el que se proclamaba literalmente: "Todo ataque de índole general contra los derechos individuales proclamados por la revolución será considerado como causa legítima de insurrección, si no se consiguiera la reparación debida por medios legales». En La Coruña, se firmó el pacto de Asturias y Galicia. En Éibar el de Euzkadi, con participación del propio Pi y Margall, esposo de la vasca Petra Arsuaga.

Duró un mes este proceso, hasta llegar a firmarse en Madrid el 30 de junio de 1869 un « pacto nacional o general» que establecía un consejo federal y en cuyo manifiesto Pi y Margall invitaba a todos los firmantes a establecer un «lazo común», aunque se reafirmaba que la estrategia del partido republicano en ningún caso estaría por encima de la soberanía de cada pacto regional. Por lo que se refiere al espinoso asunto del derecho a la sublevación armada, Pi lo solventaba de este modo: «con la libre práctica de los derechos individuales la insurrección es un crimen; sin ella, es un deber, tanto o más que un derecho. Consignar ese deber en el pacto nos ha parecido hoy no solo conveniente, sino de todo punto necesario».

Entre tanto, las Cortes cerraron sus sesiones durante el verano, desde el 15 de julio de 1869. Eso sí, habían acometido importantes medidas legislativas en materia de ferrocarriles y conservación del patrimonio histórico. Se puede afirmar que fue entonces cuando se inició una política activa de restauración y rehabilitación de monumentos y de edificios valiosos, recuperando lo que se había iniciado en 1837 y que se había dejado sin cumplir en gran parte. La consigna de regeneración nacional lanzada en 1868 significó una oleada de nacionalismo democrático de amplio consenso tanto entre liberales unitarios como entre republicanos federales, porque en ningún caso los federales tuvieron propósitos separatistas. 

se convirtieron en instrumento de reivindicación laboral y de exigencias unas condiciones de vida digna, tanto en las zonas fabriles de Cataluña, como en la artesanales de Valencia o entre los jornaleros urbanos de Madrid o entre los del campo andaluz. Chocaron con los criterios de los partidos aliados en el gobierno. En concreto, a los seis días de cerrarse las Cortes, el gobierno recuperó por decreto una ley de $17 \mathrm{de}$ julio de 1821 en la que se ponía bajo la autoridad y jurisdicción militares los delitos de «conspiración o maquinación directas contra la observancia de la Constitución, o contra la seguridad exterior e interior del Estado, o contra la sagrada e inviolable persona del rey constitucional». Una auténtica ley marcial que suspendía las garantías constitucionales al someter estos delitos a consejos de guerra. El pretexto eran las partidas carlistas, pero el gobierno comenzó a usar esa ley contra las movilizaciones sociales y protestas obreras amparadas por los federales. De hecho, los diputados republicanos, los únicos que se habían opuesto a tal decreto, volvieron a sus distritos, fueron recibidos con manifestaciones de apoyo y también de crítica al gobierno, pretexto que usó el ministro de Gobernación, Sagasta, para prohibir que participasen en tales manifestaciones los Voluntarios de la Libertad, pues eran un cuerpo armado y de orden. Además, Sagasta dio poderes excepcionales a los gobernadores civiles para reprimir motines ya contra los impuestos ya para exigir trabajo o incluso reparto de tierras. Puesto que los Voluntarios de la Libertad eran ciudadanos que participaban en tales protestas, Sagasta optó por una medida drástica, disolver los cuerpos de Voluntarios de la Libertad implicados en alguna protesta. Fue la espoleta para desencadenar una revuelta republicana en cascada por toda España.

Se produjo así el arranque de la insurrección republicana en Cataluña entre el 25 y el 28 de septiembre, con 8.000 federales armados. El Centro Federal de las Sociedades Obreras de Barcelona contaba con sindicalistas obreros como Farga Pellicer, Roca i Galés, Jaume Balasch o el internacionalista Josep Lluis Pellicer, más tarde destacado bakuninista. Defendían tanto el republicanismo federal como el cooperativismo obrero. Quemaron registros de la propiedad y archivos, cortaron vías de ferrocarril y telégrafos, exigieron derechos como el de trabajo... Fracasaron, pero a continuación se sublevó Andalucía, con más de 45.000 federales armados en los diversos ayuntamientos que se sumaron, aunque sin estar organizados como ejército. Al grito de «Viva la República Federal», los jornaleros ocuparon tierras, y exigieron tierras, trabajo y la inmediata abolición de las quintas y de la matrícula de mar, el desestanco de la sal y del tabaco, la disolución del ejército, etc. De nuevo quemaron archivos y registros de la propiedad, símbolos de esa estructura de poder que los excluía de la riqueza nacional. Tales eran los significados concretos y palpables de ese concepto de república federal. En Cádiz destacaron los activistas Paúl y Angulo y Fermín Salvoechea.

31 Prim, por una orden del 5 de octubre, suspendió las garantías constitucionales, con posibilidad de disolver las milicias de Voluntarios de la Libertad. Bastó el anuncio de la llegada de tropas para que se disolviera la mayoría y los más destacados huyeran a las serranías... En Alicante fracasó la rebelión, en Béjar no se pasó del intento, hubo resistencias heroicas en Cádiz y Málaga, pero en los casos de Zaragoza y Valencia los acontecimientos adquirieron el carácter de guerra, con auténticas batallas contra el ejército. En ambos casos se produjo una concentración de federales ayudados por campesinos de los respectivos contornos rurales que se resistieron a desarmar las milicias de Voluntarios de la Libertad. En Zaragoza resistieron cinco días, del 7 al 12 de 
octubre. En Valencia lucharon 6.000 federales contra 23.000 soldados. Era el último baluarte.

Prim gobernó de hecho con la restablecida ley de 1821 en la mano, hasta que el 10 de diciembre las Cortes derogaron el estado de excepción. En esos meses Prim sofocó y reprimió la rebelión federal, disolvió las compañías de Voluntarios de la Libertad sospechosas de republicanismo. Por otra parte, el fracaso de esta cadena de revoluciones espontáneas y desorganizadas afianzó el liderazgo de Pi y Margall, partidario de los cauces legales para alcanzar la república federal. Pi logró que los diputados federales volvieran a las Cortes y derrotó a Castelar en la pugna entre federalismo y unitarismo. En 1870 fue elegido presidente de los republicanos que además establecieron un directorio federal por encima de los pactos regionales, insistieron en el carácter pacífico del partido e intensificaron la propaganda como cauce de expansión y convencimiento, aunque no por eso importantes sectores federales dejasen de defender la necesidad de la «intransigencia revolucionaria».

\section{La esclavitud y el obstruccionismo a la monarquía democrática}

Desde que el gobierno de Ruiz Zorrilla hiciera de la abolición de la esclavitud y de las reformas en las Antillas una cuestión de Estado, todo valía para boicotear sus proyectos y en esa tensión transcurrió su gobierno desde agosto de 1872 hasta febrero de 1873 . Por otra parte, la guerra ofrecía un trágico saldo de 25.000 bajas, con más de 74.000 soldados o quintos destinados en Cuba. El precio en hombres era demasiado elevado, también el gasto para el erario público. Si se quería salvar el sistema democrático, había que dar soluciones tanto a la guerra cubana como la insurrección carlista, pero, mientras tanto, el gobierno de Ruiz Zorrilla, nada más abrir las Cortes, tuvo que reclutar a 40.000 quintos más. No pudo cumplir la promesa de abolir el sistema de quintas, aunque comenzó a tramitar el proyecto de ley de ayuntamientos para las Antillas y el de abolición definitiva de la esclavitud, ambos con el poderoso rechazo del Centro Hispano-Ultramarino de Madrid, que orquestó una fabulosa campaña antigubernamental por las ciudades más importantes de España, con los Güell y Antonio López al frente, entre otros.

No existían precedentes para tan extraordinario grupo de presión en la vida de un sistema democrático tan joven. El 3 de diciembre de 1872 se reunieron, por ejemplo, los integrantes del centro hispano-ultramarino de Valencia que rechazaron las reformas del gobierno por «impolíticas y antipatrióticas», dos calificativos que harían fortuna al tachar de antipatriótico cuanto se opusiera a sus intereses. La ofensiva avanzó y todos los centros hispano-ultramarinos, con el marqués de Manzanedo como portavoz, exigieron directamente al rey ser «el primer guardador de los derechos patrios y defensor de la integridad del territorio». Se les sumaron los unionistas de Serrano y los conservadores Cánovas y Romero Robledo quien, con virulencia, anunciaba el plan de «oponer al gobierno una resistencia poderosa... y sacrificar vidas y haciendas, emprenderlo todo». Por supuesto, los carlistas también se unieron a la campaña. En la asamblea celebrada en Madrid el 14 de diciembre decidieron por unanimidad impedir la reforma y hacer saber al rey Amadeo que estaba en juego su monarquía. protagonizó el brigadier Pozas, luego fugado al bando carlista, una extraña connivencia 
que llevó a un serio debate en el seno del partido republicano. Costó grandes esfuerzos mantener la unión, porque Pi y Margall, Castelar y Roque Barcia condenaron las actitudes insurgentes, pero de nuevo la recluta de más quintos fue pretexto para que sectores republicanos tomaran las armas. Este recurso a la insurrección armada demostraba la profunda división entre los federales de Pi y Margall, partidarios de actuar en los cauces legales, y aquellos republicanos intransigentes que exigían la revolución social y organizaban comités secretos dentro del propio partido.

Mientras tanto, los carlistas, que, gracias al general Serrano, contaban con el estatuto de potencia militar cuasi estatal, se reunían para lograr fondos y recaudaban impuestos en las zonas bajo su control. No obstante, y a pesar de la gravedad de la violencia de las guerrillas carlistas, el acoso más serio y peligroso para la monarquía democrática estaba en esa Liga Nacional constituida contra la abolición de la esclavitud y las reformas en las Antillas. Fue este grupo de presión el que cercó al gobierno de Ruiz Zorrilla. Cuando el 24 de diciembre llegó a las Cortes el proyecto de ley abolicionista, el día de navidad se reunió la diputación de la nobleza española, con el marqués de Molins, Mariano Roca de Togores al frente, y también se lanzó contra el gobierno.

El gobierno no cedió. El 10 de enero de 1873 hubo otro manifiesto de la Liga Nacional contra el gobierno y el día 15 se reanudaron las sesiones de las Cortes con medidas como la secularización de los cementerios, la reforma de impuestos sobre títulos y cruces de la aristocracia, el reemplazo del ejército y el proyecto de abolición de quintas y matrícula de mar, dedicando incluso las noches a sesiones maratonianas para aprobar los presupuestos. La Liga Nacional de oligarcas peninsulares y esclavistas insulares arreció en sus movimientos. No dieron respiro al gobierno, resucitaron de nuevo el conflicto de los artilleros, un asunto de corporativismo militar de limitada importancia que obligó al gobierno a reorganizar el cuerpo de artillería la primera semana de febrero con otros suboficiales.

Así las cosas, Ruiz Zorrilla tenía previsto el debate parlamentario de la abolición de la esclavitud en Puerto Rico para el 9 de febrero. Sin embargo, el rey, que había firmado el decreto de reorganización del cuerpo de artillería, ya no encontró más fuerzas personalmente para hacer frente a tanta presión. Zorrilla no logró convencerlo para que no dimitiera. Rivero reunió ambas cámaras constituyéndolas en convención, aunque contravenía lo previsto en el artículo 47 de la Constitución. Sin duda, la Liga Nacional había logrado su objetivo de paralizar las reformas en las Antillas. Sin estar previsto por los partidos, se llegó así a proclamar la República en sesión conjunta de ambas cámaras. Era el 11 de febrero.

\section{La República: el plan de reformas sociales y el cúmulo de conflictos}

De los contenidos modernizadores de esta experiencia republicana cabe destacar tres dimensiones del proceso de modernización. En primer lugar, la eclosión del reformismo social como prioridad política; en segundo lugar, las demandas de descentralizar la soberanía del poder central para ampliar los espacios de democratización ciudadana, y, por último, los dilemas de un gobierno democrático para armonizar el orden con el desbordamiento de las demandas ciudadanas. 

ejemplo, en Málaga se incendiaron las aduanas y se atacaron las propiedades del Estado. Los campesinos de Montilla, tantas décadas sometidos al fraude caciquil, saquearon la casa del alcalde el 12 de febrero, quemaron los archivos locales y mataron a varios empleados municipales. Era el odio del pobre contra el rico, según el notario e historiador Díaz del Moral, pero el hecho es que esos sucesos dieron motivo para que la prensa monárquica, en gran parte alfonsina, con La Época al frente, diera pábulo a la noticia y propagase desde el primer día la sensación de que república era sinónimo de caos... En otra parte de España, el 21 de febrero, en la plaza de Sant Jaume de Barcelona los ciudadanos se manifestaban para pedir el Estado catalán. Las diputaciones catalanas acordaron constituirse en Estado federal, quitaron a los militares el mando y los convirtieron en un ejército de voluntarios. cuando se pensó por primera vez que el Estado tenía que asumir tareas que suponían los esbozos y peldaños de lo que hoy consideramos como derechos sociales. En este sentido, tras celebrarse las elecciones para una Asamblea constituyente con un amplio triunfo de los republicanos, Pi y Margall pudo anunciar en el discurso de apertura de dicha Asamblea la necesidad de elaborar con rapidez la Constitución pero sobre todo abordar reformas tan urgentes como el reparto de la propiedad agraria, los jurados mixtos de obreros y fabricantes, el control del trabajo de los niños, la efectiva implantación de la enseñanza pública, gratuita y obligatoria, la separación de la iglesia y Estado y la abolición, al fin, de la esclavitud en Cuba. Por eso pidió unión a todos los federales para salvar la república a la vez que prometió la ley pendiente de suspensión de garantías constitucionales para armonizar la necesidad de orden público con las libertades ciudadanas.

Era un programa que recogía viejas aspiraciones que ya se habían planteado incluso entre los diputados de la revolución liberal del Cádiz de 1812. Rescataba la antigua propuesta de vender a censo reservativo los bienes nacionales para las clases jornaleras, tal y como habían defendido Flórez Estrada, Romero Alpuente y otros diputados del trienio constitucional, allá por 1820. Así, para resolver el largo litigio sobre la propiedad de las tierras de señorío, se creó en mayo de 1873 una comisión que elaboró todo un plan de reforma agraria en el que se planteaba dar trabajo a los jornaleros en tierras comunales y de propiedad municipal, anular los jornales ilegales y establecer la propiedad colectiva de bosques y pastos controlados por los ayuntamientos. Esto hizo temblar a las clases propietarias.

43

Había más asuntos en el programa de los federales, igualmente decisivos para mejorar las duras condiciones de vida de la mayoría. Así, se planteó reducir la jornada laboral a 9 horas, establecer un salario mínimo por primera vez en la historia de España, calculado entonces en 6 reales, prohibir el trabajo de los niños en edad escolar y regular las condiciones de higiene en que debían trabajar en las manufacturas las mujeres, consideradas el sexo débil. Otro avance muy significativo fue la previsión de un sistema de jurados mixtos para arbitrar los conflictos laborales. En esta línea reformista, pensaron también en suprimir la herencia colateral y dejar sólo una quinta parte para herencia directa al beneficiario, de tal modo que el derecho de sucesión no pasara de ser una quinta parte de los bienes. También preveían la expropiación sin indemnización por utilidad pública, así como expropiar aquellas tierras cuyos dueños las tuviesen sin cultivar un mínimo de cuatro años. 

1873 sonaron a socialismo revolucionario. No por casualidad dos diputados federales como el jerezano Ramón de Cala, director del periódico La Igualdad, y el onubense Francisco Díaz Quintero (entonces representando a Badajoz) se definían a sí mismos como socialistas. Por su parte, Pi y Margall era consciente de que estas reformas sociales podrían aportar estabilidad a la nación española, porque borrarían las nuevas desigualdades creadas por el modo en que se habían llevado las privatizaciones de las tierras de señoríos eclesiásticos, solariegos y de realengo, y porque reforzarían el republicanismo como proyecto de libertad y fraternidad ciudadana. La Constitución, aunque no llegase a ser promulgada, expresó tales afanes. Ante todo, en la presentación del texto se declaraba que «asegurar la libertad, cumplir la justicia y realizar el fin humano a que está llamada en la civilización» son metas para una colectividad definida rotundamente como «Nación Española». En consecuencia, en el título preliminar, soporte del resto de los títulos constitucionales, se establecía: «Toda persona encuentra asegurados en la República, sin que ningún poder tenga facultades para cohibirlos, ni ley ninguna autoridad para mermarlos, todos los derechos naturales». Y a continuación se hacía una declaración de derechos humanos que concluía con una fórmula imperativa y vinculante: «estos derechos son anteriores y superiores a toda legislación positiva». española». Constaba de dos artículos, el primero para definir España como una nación compuesta por los Estados de Andalucía Alta, Andalucía Baja, Aragón, Asturias, Baleares, Canarias, Castilla la Nueva, Castilla la Vieja, Cataluña, Cuba, Extremadura, Galicia, Murcia, Navarra, Puerto Rico, Valencia y Regiones Vascongadas; y el segundo, para precisar que las islas Filipinas, Fernando Poo, Annobón, Corisco y los establecimientos de África eran «territorios [españoles] que, a medida de sus progresos, se elevarán a Estados por los poderes públicos». Se establecía un Senado, con cuatro senadores elegidos por los parlamentos de sus respectivos Estados regionales, con unas competencias bien definidas: «exclusivamente examinar si las leyes del Congreso desconocen los derechos de la personalidad humana, o los poderes de los organismos políticos o las facultades de la Federación, o el Código fundamental».

46 En el título II, al detallar los derechos ciudadanos, se establecía la novedad de que «la enumeración de los derechos expresados en este título no implica la prohibición de cualquier otro no declarado expresamente». Como deberes se estipulaba la obligación de defender la Patria con las armas, por un lado, y, por otro, el de «contribuir a los gastos del Estado en proporción de sus haberes». También se separaba expresamente la Iglesia del Estado y se prohibía a «la Nación o Estado federal, a los Estados regionales y a los Municipios subvencionar directa o indirectamente ningún culto».

Los títulos III al XIV se destinaban a la regulación de la separación de los tres poderes clásicos (legislativo, ejecutivo y judicial), así como a las relaciones entre los niveles de soberanía compartida por el municipio, el Estado regional y el Estado federal o Nación. Por otra parte, se constataba que el republicanismo no era sino la máxima expresión de los principios liberales cuando en el artículo 42 se insistía en que «la soberanía reside en todos los ciudadanos, y se ejerce en representación suya por los organismos políticos de la República constituida por medio de sufragio universal». Unos organismos (el Municipio, el Estado regional y el Estado federal) sometidos todos ellos a «los límites de los derechos de la personalidad humana». 

«nuevo orden de cosas» que permitiría «la armonía social». Se pensaba que la organización del poder desde abajo abriría el camino a la fraternidad ciudadana de personas y pueblos. La realidad, sin embargo, transcurrió por otros derroteros. Los Voluntarios de la República se convirtieron en plataformas armadas donde federales e internacionalistas optaron por resolver las demandas populares con la máxima urgencia. Por ejemplo, en Málaga los internacionalistas desbordaron a los federales, se impusieron al ejército y a finales de marzo la ciudad contaba con diez mil trabajadores armados con cargo a un impuesto que el ayuntamiento republicano había decretado para las clases propietarias. La conflictividad campesina se extendió no solo por toda Andalucía sino también por la Galicia forera y entre los arrendatarios y aparceros de Valencia y Cataluña.

位 Andalucía y Extremadura y amplió el pánico de las clases propietarias, dispuestas a financiar cuanto fuese necesario para derribar la República. En tal contexto, Pi y Margall, hombre fuerte desde el 11 de febrero, no pudo calmar a sus correligionarios intransigentes que en el mes de julio se sublevaron contra la política de «orden y progreso». Sin pormenorizar detalles y acontecimientos que marcaron el levantamiento cantonal, interesa subrayar los contenidos sociales y políticos que albergó aquel movimiento tan caótico de exasperación en el que se mezclaron activistas profesionales con obreros y sectores populares anhelantes de mejoras inaplazables.

50 En concreto, el periódico El Cantón Murciano publicó un plan de gobierno para toda España. Proclamaron la urgencia de legislar la redención las rentas feudales vigentes en poblaciones de toda la geografía española, fuesen las rentas forales en Galicia y Asturias o las prestaciones señoriales vigentes en muchas localidades, citando casos como los miles de celemines de cebada cuyo equivalente en metálico todavía pagaban 20 pueblos de León y Segovia cada año al duque de Sesto, que no por casualidad era el principal conspirador para restaurar la monarquía borbónica. En suma, exigían abolir «todos los efectos legales de los títulos supletorios con que el feudalismo se apoderó de una gran parte de nuestra tierra», esto es, replanteaban el modo en que se habían suprimido los señoríos en 1837 y declaraban que todo español tenía derecho a pedir los títulos necesarios para averiguar el valor o precio de las tierras vendidas por reyes o señores feudales. Por eso suprimían el registro de la propiedad y los sustituían por uno municipal gratuito. Por otra parte, los cantonales declararon propiedad de los municipios cuantas fincas estuviesen sin cultivar por sus dueños durante cinco años. Así, con estas tierras y con las comunales el Estado se harían lotes a censo redimible para establecer unos colonos que significarían el fin de «la raza de los siervos, verdaderos esclavos blancos». Trataban, en definitiva, de reorganizar la riqueza nacional, consistente sobre todo en la propiedad de la tierra, pues estábamos en una sociedad agraria.

51 En otro orden de cosas, los cantonales reorganizarían la gestión pública con medidas propias de una nueva cultura política. Por ejemplo, que ningún sueldo pasivo excedería de los 12.000 reales y ningún sueldo público de la península pasaría de los 2.000 duros; se suprimían los coches concedidos a los funcionarios, y se abolían los gastos imprevistos y gastos secretos. Más decisiva era la contribución sobre el capital, como también la creación de bancos agrícolas, industriales y mercantiles para favorecer el 
«desarrollo de la riqueza desamortizada, de matar la usura y crear familias laboriosas y honradas», siempre con un rédito no superior al 3 por ciento en estos bancos.

En todo caso, la sublevación cantonal dividió definitivamente a los federales. Los seguidores de Castelar y de Salmerón temían que el caos producido por los cantonales facilitaría el triunfo de la reacción carlista. Eran mayoría en la Asamblea constituyente y lograron que Salmerón sustituyera a Pi y encomendaron el sometimiento de los cantones a tres generales de simpatías monárquicas. La imprevista dimisión de Salmerón y la votación de Castelar para presidir el gobierno supuso un cambio de rumbo. La Asamblea dio plenos poderes a Castelar para acabar con la guerra carlista y decidió suspender sus sesiones hasta el 2 de enero. El otoño de 1873 transcurrió con la atención puesta en acabar con el ejército carlista y en alcanzar soluciones políticas para el 2 de enero, cuando terminara el periodo de excepcionalidad de Castelar. Conforme se avecinaba la fecha del 2 de enero con las Cortes en pleno, las maniobras y las tensiones contra la República se acrecentaron, mientras no cejaban las divisiones entre los republicanos. El propio Castelar no había podido desmentir que la Asociación de Hacendados de Cuba, los negreros, estaban financiando a los carlistas. El asunto de la esclavitud persistía como catalizador de todas las dificultades de la República.

Pero llegados a este punto, de la concatenación de hechos que llevaron a la República autoritaria del general Serrano y a la posterior restauración de la monarquía borbónica, baste con subrayar que el propio Serrano había apoyado a la antigua Liga Nacional negrera y que su primera decisión fue suspender las garantías constitucionales y deportar a más de cinco mil destacados militantes internacionalistas y cantonalistas a las islas Marianas, de donde nunca volverían.

En definitiva, a modo de conclusión, cabe destacar que, por encima de los conflictos y las dos guerras, durante este Sexenio Democrático se anudó el legado de la generación política y cultural de 1868, el primer peldaño en el proceso de transformación del Estado liberal en un Estado democrático de derecho. A pesar de ser la primera vez en que empieza el transcurrir de una España democrática, con una experiencia como la republicana, la bibliografía no es excesiva. Comparando con la Restauración y con la segunda República, los estudios sobre estos años son mucho menos abundantes. Con independencia del atractivo que tiene cada etapa histórica, sin duda estos seis años concentraron acontecimientos, procesos y conflictos decisivos en la historia contemporánea de España. Cada año tuvo tal densidad de novedades, que por eso es justo plantear la necesidad de seguir profundizando en sus entresijos.

\section{BIBLIOGRAFÍA}

\section{BIBLIOGRAFÍA}

ANGUERA NOLLA, Pere, Propaganda política i processos electorals al Baix Camp, 1869-1873, Reus, Associació d' Estudis Reusencs, 1985. 
BERDIÉ BUENO, Isidoro, Aragón durante la Revolución de septiembre (1868), Zaragoza, Mira ed., 1991. CANAL MORELL, Jordi, El carlismo. Dos siglos de contrarrevolución en España, Madrid, Alianza, 2000. CALERO AMOR, Antonio M. ${ }^{-}$, Monarquía y democracia en las Cortes de 1869. Discursos parlamentarios, Madrid, C.E.C, 1987.

CARO CANCELA, Diego, Burguesía y jornaleros. Jerez de la Frontera en el sexenio democrático, 1868-1874, Jerez, 1990.

CARo CANCELA, Diego (ed.), La revolución de 1868 en Andalucía, Jerez, Peripecias Libros, 2018

CATALINAS, JosÉ LUIS Y ECHENAGUSÍA, Javier, La Primera República. Reformismo y revolución social, Madrid, Alberto Corazón ed., 1973

CEPERO BONILla, Raúl, Azúcar y abolición, Barcelona, Crítica, 1976

DíAZ GARCíA, Elías, La filosofía social del krausismo español, Madrid, Edicusa, 1973.

DUARTE MONTSERRAT, Ángel, «Nación de republicanos. Siglo XIX», en Historia de la nación y del nacionalismo español / coord. por Antonio MORALES MOYA, Juan Pablo FUSI, Andrés de BLAS GUERRERo, 2013, p. 293-306.

ESPIGADO TOCINO, Gloria, La primera República en Cádiz. Estructura social y comportamiento político durante 1873, Jerez-Sevilla, 1993

FUENTE MONGE, Gregorio de la, Los revolucionarios de 1868: elites y poder en la España liberal, Madrid, Marcial Pons, 2000.

GIL CREMADES, Juan José, El reformismo español. Krausismo, escuela histórica, neotomismo, Barcelona, Ariel, 1969

GONZÁLEZ RodRíGUEZ, Candelaria, El Sexenio Democrático en Las Palmas (1868-1874): continuidad y cambio en las estructuras de poder, Universidad de las Palmas. Tesis doctoral, 2015.

GUTIÉRREZ LLORET, Rosa Ana, Republicanos y Liberales. La Revolución de 1868 y la Primera República en Alicante, Alicante, Inst. Gil-Albert, 1985

HENNESY, C.A.M., La República federal en España. Pi y Margall y el movimiento republicano federal, 1868-1874, Madrid, Aguilar, 1966.

HIGUERAS CASTAÑEDA, Eduardo, Con los Borbones, jamás. Biografía de Manuel Ruiz Zorrilla (1833-1895), Madrid, Marcial Pons, 2016

IGLESIAS GONZÁLEZ, Soledad, Soria en el Sexenio democrático, 1868-1874, Madrid, Ed. Complutense, 1989 JANUÉ I MIRET, Marició, La Junta Revolucionaria de Barcelona a l'any 1868, Vic, Institut Univ, d'Història J. Vicens, Eumo ed., 1992.

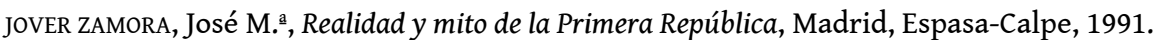

LA PARRA, Emilio Y SUÁREZ CORTINA, Manuel (eds.), El anticlericalismo español contemporáneo, Madrid, Biblioteca Nueva, 1998

LIDA, Clara Y ZAVALA, Iris M., La revolución de 1868. Historia, pensamiento, literatura, Nueva York, 1970 MIRA ABAD, Alicia, Actitudes religiosas y modernización social. La prensa alicantina del sexenio democrático (1868-1873), Alicante, Publicaciones de la Universidad, 1999

MORALES NUÑOZ, Manuel, Economía y sociedad en la Málaga del siglo XIX. Aproximación a la historia social del "sexenio revolucionario", Málaga, Diputación provincial, 1983. 
NAVARRO AZCÚE, Concepción, La abolición de la esclavitud negra en la legislación española, 1870-1886,

Madrid, ICI, 1987.

PÉREZ CRESPO, Antonio, El Cantón Murciano, Murcia, Academia Alfonso X el Sabio, 1990.

PÉREZ GARZÓN, J. Sisinio, «El sexenio democrático, 1868-1874», en Historia contemporánea de España, 1808-1923 / coord. por Blanca Esther BULDAIN JACA, 2011, Madrid, Akal, p. 273-370.

PIQUERAS ARENAS, José A. Y SEBASTIÀ, Enric, Agiotistas, negreros y partisanos, Valencia, Alfons el

Maganánim, 1991.

PIQUERAS ARENAS, José A., La revolución democrática (1868-1874). Cuestión social, colonialismo y grupos de presión, Madrid, Ministerio de Trabajo, 1992.

SÁNCHEZ MARROYO, Fernando, Movimientos populares y Reforma Agraria. Tensiones sociales en el campo extremeño durante el sexenio democrático, 1868-1873, Badajoz, Diputación provincial, 1992.

SEBASTIÀ DOMINGO, Enric Y PIQUERAS ARENAS, José A., Pervivencias feudales y revolución democrática, Valencia, Alfons el Magnànim, 1987.

SERRANO GARCíA, Rafael, España, 1868-1874. Nuevos enfoques sobre el Sexenio Democrático, Valladolid, Junta de Castilla y León, 2002.

SERRANO GARCÍA, Rafael, «Historiografía reciente en torno a la revolución "Gloriosa" y el Sexenio Democrático (1868-1874)», en Diego CARO (ed.): La revolución de 1868 en Andalucía, Jerez, Peripecias Libros, 2018, pp. 14-44.

SERRANO GARCíA, Rafael, La revolución de 1868 en Castilla y León, Valladolid, Publicaciones de la Universidad, 1992.

TERMES, Josep, Anarquismo y sindicalismo en España. La Primera Internacional, 1864-1881, Barcelona, Ariel, 1977.

TRÍAS BEJARANO, Juan, Francisco Pi y Margall. Pensamiento social, Madrid, Edicusa, 1968. VILAR, Juan Bautista, El Sexenio Democrático y el Cantón Murciano, 1868-1874, Murcia, Institución Alfonso X, 1983. VILLACORTA BAÑOS, Francisco, Burguesía y cultura. Los intelectuales españoles en la sociedad liberal, 1808-1931, Madrid, Siglo XXI, 1980.

VILLARES PAZ, Ramón, La propiedad de la tierra en Galicia, 1500-1936, Madrid, Siglo XXI, 1982.

VILLENA ESPINOSA, Rafael: El Sexenio Democrático en la provincia de Ciudad Real: economía, política y sociedad (1868-1874), Cuenca, Editorial Universidad de Castilla-La Mancha, 1997.

\section{NOTAS}

1. El presente texto se ha redactado como reflexión sobre los significados y legados que cabe ser valorados desde el presente. Se omite, por tanto, el aparato académico de notas bibliográficas y documentales para facilitar la lectura y se expone al final la bibliografía más imprescindible sobre el período, aunque no se hace exhaustivamente. 


\section{RESÚMENES}

El proceso de modernización política y socioeconómica ha sido el factor de cambio que ha marcado la historia de España desde la Cortes de Cádiz en 1810 hasta la Constitución democrática de 1978. Dos siglos XIX y XX que no han sido ni unilineales ni pacíficos. En ese arco temporal hay que destacar el sexenio de 1868 a 1874 como el momento en que por primera vez en España se proclamaron los derechos humanos como «imprescriptibles, inalienables e ilegislables». Además, se determinó que la soberanía solo era nacional si se organizaba como popular y democrática, que la cultura era tan libre como plural, y que toda la sociedad debía organizarse sobre principios de justicia y organización equitativa de una riqueza definida como nacional, aunque hasta entonces estuviese acaparada por unos pocos. Por eso es justo destacar el legado de la generación política y cultural de 1868, el primer peldaño en el proceso de transformación del Estado liberal en un Estado democrático de derecho.

The process of political and socio-economic modernization has been the factor of change that has marked the history of Spain from the Cortes de Cádiz in 1810 to the democratic Constitution of 1978. Two centuries, 19 th and $20^{\text {th }}$, that have been neither unilinear nor peaceful. The six-year period from 1868 to 1874 should be highlighted as the first time in Spain that human rights were proclaimed as "imprescriptible, inalienable and illegible". Furthermore, it was determined that sovereignty was only national if it was organized as popular and democratic, that culture was as free as it was plural, and that the whole society should be organized on the principles of justice and equitable organization of a wealth defined as national, although until then it had been monopolized by a few. Therefore, it is fair to highlight the legacy of the political and cultural generation of 1868 , the first step in the process of transforming the liberal state into a democratic state based on the rule of law.

Le processus de modernisation politique et socio-économique a été le facteur de changement qui a marqué l'histoire de l'Espagne, des Cortès de Cadix en 1810 à la Constitution démocratique de 1978. Deux siècles, le XIXe et le XXe, qui n'ont été ni unilinéaires ni pacifiques. Dans cet arc temporaire, la période de six ans allant de 1868 à 1874 doit être mise en évidence comme le moment où, pour la première fois en Espagne, les droits de l'homme ont été proclamés « imprescriptibles, inaliénables et illisibles ». Il a également été déterminé que la souveraineté n'était nationale que si elle était organisée comme populaire et démocratique, que la culture était aussi libre que plurielle et que la société dans son ensemble devait être organisée selon les principes de justice et d'organisation équitable d'une richesse définie comme nationale, bien que, jusque-là, elle ait été monopolisée par quelques-uns. C'est pourquoi il est juste de souligner l'héritage de la génération politique et culturelle de 1868, première étape du processus de transformation de l'État libéral en un État de droit démocratique.

\section{ÍNDICE}

Mots-clés: Espagne, Sexennat démocratique, État libéral, Modernisation sociale et politique, Démocratisation.

Palabras claves: España, Sexenio Democrático, Estado liberal, Modernización social y política, Democratización.

Keywords: Spain, Democratic Sexenio, Liberal State, Social and Political Modernization, Democratization. 


\section{AUTOR}

JUAN SISINIO PÉREZ GARZÓN

Universidad de Castilla-La Mancha 